\title{
Refractive Error in Children
}

\section{Hina Y. Rodge ${ }^{1}$, Shalini Lokhande ${ }^{2}$}

\section{IJCRR}

Section: Healthcare

Sci. Journal Impact

Factor: 6.1 (2018)

ICV: 90.90 (2018)

(c) (i) (3)

Copyright@IJCRR
'MSc. Nursing Student, Department of Child Health Nursing, Smt. RadhikabaiMeghe Memorial College of Nursing, Datta Meghe Institute of Medical Sciences (Deemed to be University) Sawangi (M), Wardha, Maharashtra, India; ${ }^{2}$ Assistant Professor, Department of Child Health Nursing, Smt. RadhikabaiMeghe Memorial College of Nursing, Datta Meghe Institute of Medical Sciences (Deemed to be University) Sawangi (M), Wardha, Maharashtra, India.

\section{ABSTRACT}

Refractive error may occur if the eye fails to precisely focus a light beam from an element onto the retinal surface. The resulting image perceived by the individual is blurred and correction of the refraction is required to see clearly. Refractive deficiency is often known as "Short or Near-sightedness", hypermetropia or hyperopia often called "Long or Far-sightedness", presbyopia and astigmatism. Vision is vital in the development of the children as it enables children to engage with their atmosphere. The eyesight of pre-school children is vitally important since their sensory system continues to be developing and that they are danger of developing Amblyopia or Anisometropia. Additionally, refraction Defects are risk factors for different Ocular diseases. Uncorrected refraction errors are a significant reason for visual disablement and can result in productivity loss. Refractive error has been identified among vision problems alongside cataract, trachoma, onchocerciasis and childhood blindness, the diagnosis and treatment of which will offer tremendous savings and socioeconomic growth. About 150 million individuals worldwide have a visual disability due to uncorrected Refractive Error, 8 million of who are practically blind. In the year 2010, The refractive error impacted 1.45 billion men or $27 \%$ of the world's population. By 2020 , it is reported that only myopia will impact 2.5 billion individuals or one per cent of the population worldwide. Childhood Visual Impairment is amongst the common issues of school-age kids due to refractive error and the second most significant cause of treatable blindness.

Key Words: Refractive error, Risk factors, Children, Myopia, Hypermetropia

\section{INTRODUCTION}

The human eye is a magnificent organ that gives us the sense of sight that allows us to see and know more about the world around us than we do with any of the other four senses. The learning target starts in infancy and the quality of a child's vision will have a significant effect on his / her ability to learn. It helps to decide an individual's future where eyesight has a significant part to play in. Also, planning the Youth professions are highly dependent on visual acuity, especially in the maritime, military, rail, and aviation industries. To avoid permanent damage, this requires premature identification and treatment of refractive defect. ${ }^{1}$

Refractive error (RE) is one of the commonest vision disability causes in the world and the second-largest cause of treatable blindness. ${ }^{2}$ Approximate 2.3 billion people worldwide have a refractive defect, but only 1.8 billion people have access to eye tests and effective treatment. ${ }^{3}$ The World Health
Organization (WHO) initiated management of refractive errors by 2020 and for its urgency puts it in the fifth position. ${ }^{4,5}$ For the reduction of avoidable blindness in the Global Initiative 2020. Refractive errors were emphasized in combination Many vision problems include cataract, trachoma, and onchocerciasis. $^{6}$

Different research in South India records the prevalence of refractive errors ranging from 5 to 25 percent. ${ }^{7-9}$ Children of school age are an especially vulnerable group as the uncorrected blurred vision may have a drastic effect on learning and educational ability. ${ }^{10}$ Those teachers who don't know the root issue the children are calling them lazy. Visual acuity screenings do not diagnose their outcomes may show an expected requirement for additional evaluation. Optical sight correction is of comparatively low-cost quality. The proportion of children with visual impairments due to refractive error can be used to determine the level of advancement in eye care services in a country. They also assume that, when

\section{Corresponding Author:}

Hina Y. Rodge, MSc. Nursing Student, Department of Child Health Nursing, Smt. RadhikabaiMeghe Memorial College of Nursing, Datta Meghe Institute of Medical Sciences (Deemed to be University) Sawangi (M), Wardha, Maharashtra, India; Email: hinarodge76@gmail.com

ISSN: 2231-2196 (Print)

Received: 20.06 .2020
ISSN: $0975-5241$ (Online)

Revised: 13.08 .2020
Accepted: 20.09 .2020
Published: 07.12 .2020 
wearing appropriate glasses at an early age, the severity of the refractive error issue requires a thorough evaluation of vision and correction. Although regional efforts are targeted at reducing blindness, the number of children experiencing refractive error continues to increase every day. This may be attributed to a lack of knowledge of the risk factors and risks caused by refractive errors. ${ }^{11}$

This situation was regarded as among the goals of 'Vision 2020': "Right to See", a worldwide activity initiated by an alliance of NGOs and the World Health Organization, leading to the awareness of the tremendous need to fix refractive errors worldwide. ${ }^{12,13}$ Refractive distortion is often referred to as a refractive errors precise problem that focuses light rays on retina primarily because of eye shape. ${ }^{14}$ The four commonest refractive errors are myopia also called 'Short or Nearsightedness', hypermetropia or hyperopia also called 'Long or Farsightedness', Astigmatism and Presbyopia. ${ }^{14} \mathrm{~A}$ refractive error is an ocular condition which is very common. This occurs when the body can't focus on visual stimuli. Blurred vision is the result of the refractive errors and often so extreme that it causes vision loss. Refractive error cannot be prevented, but eye tests may use to diagnosed and treat the new spectacles, contact lenses, or refractive operation. If the refractive error has been treated in time and by eye care experts, the complete production of good visual function is not impeded. ${ }^{15}$ Correction is made in various forms depending on the defect, the age of the individual, the activity requirement. $^{16}$

\section{Definiation}

Refractive error, also referred to as a refraction error, is a problem that focuses light rays on the retina primarily because of the shape of the eye. ${ }^{14}$

\section{TYPES OF REFRACTIVE ERROR}

Overuse of the eyes does not cause a refractive error or exacerbate it. ${ }^{17}$

Myopia (Nearsightedness): The ability to see things close by more clearly than things far away. Nearsightedness is typically hereditary and frequently observed in adolescence. Nearsightedness regularly an advance all through the adolescent years when the body develops quickly. ${ }^{17}$ Myopia causes impaired visual acuity in both school children and adults and it accounts for a major percentage of refractive error. ${ }^{18}$

Hypermetropia (Farsightedness): Long-sightedness, farsightedness also called hyperopia or hypermetropia may be also hereditary. Youngsters frequently have hypermetropia, which may reduce in adulthood. This happens with eyeballs lengthen as they grow. Distance vision in mild hypermetropia is perfect, whereas nearly sight is blurred. Vision can be distorted any distance in advanced hypermetropia. ${ }^{17}$

Astigmatism: Astigmatism tends to happen when the cornea has an asymmetrical curvature at the front of the eye. The cornea is usually smooth and equally rounded in both directions and the light rays entering the cornea are equally entered on the planes or both directions. This irregularity may bring about vision that is a lot of like investigating a twisted, wavy mirror. Astigmatism normally triggers a blurry sight on any range. ${ }^{17}$ Astigmatism is frequently not detected during routine school eye screening. ${ }^{19}$

Presbyopia: The word 'Presbyopia' comes from the Greek for "elderly vision." Presbyopia is associated with ageing. It occurs in everyone. The eyes lens becomes more rigid after 40 and doesn't flex as quickly. Therefore, the eye loses its entering force and it turns out to be increasingly hard to peruse at short proximity. This ordinary maturing procedure of the focal point can likewise be joined with nearsightedness, hypermetropia or astigmatism. ${ }^{17}$

\section{EPIDEMIOLOGY}

It is estimated that more than 150 million people globally suffer a visual loss due to uncorrected refractive error, of which 8 million are essentially blind..$^{20}$ In 2010 refractive error affected 1.45 billion people or $27 \%$ of the world's population. ${ }^{21}$ There are 365 million children $<15$ years of age or 29 per cent of the population in India as of January 2017; the National Health Profile, released by the Government of India; hence providing visual screening for all children is a challenging task. ${ }^{22}$ In India, children registered differing prevalence levels of myopia and hyperopia. ${ }^{23,24,25}$ These studies have shown that several children require fantastic correction and in rural India, about $86 \%$ of children require refractive error without correction. ${ }^{23}$

\section{CAUSES}

The refractive error could because:

- Eyeball range (where the ball grows too long or too short $)^{26}$

- Corneal type complications (clear outer layer of the eye $)^{26}$

- Lens ageing (an inner portion of the eye that is usually transparent and helps to guide the vision) ${ }^{26}$

\section{RISK FACTORS}

\section{- Genetics}

Persons with family members with refractive errors are much more likely to suffer similar refractive errors. ${ }^{14}$ 


\section{- Environmental}

$\checkmark \quad$ Among hereditary predisposition studies of Refractive Error, there is a link between environmental conditions and risk factors for developing near-sightedness. ${ }^{27}$

$\checkmark \quad$ Myopia of people with visually active jobs was found 28

$\checkmark$ Reading was shown to be a marker of myopia in children. Kids with myopia have been recorded to have spent considerably more time reading than kids without myopia who have spent a lot of time outside playing. ${ }^{28}$

$\checkmark \quad$ The risk of myopia has been reported to be the socioeconomic status and higher education levels.

\section{SYMPTOMS}

- Blurry vision is the most common symptom. ${ }^{26}$

Many signs include:

- Double vision, hazy vision, haze or halo in bright lights, squinting, headache, the pain of the eyes (whether the eyes are exhausted or sore), and difficulty concentrating while reading or watching a screen. ${ }^{26}$ The crossing of eyes in children (esotropia). ${ }^{17}$

\section{SCREENING}

An eye care practitioner can diagnose a refractive error during a regular eye examination. Testing usually involves the patient reading a chart of vision when checking the lens range to optimize a patient's vision. Rarely require advanced imaging or other studies. ${ }^{17}$

\section{MANAGEMENT}

\section{Medical approach}

- $\quad$ Spectacles, Contact Lenses ${ }^{17}$

\section{Surgical approach}

- Surgery: Laser surgery ${ }^{17}$

\section{Nursing approach}

$\checkmark \quad$ Educating about eyeglasses

$\checkmark$ Educating about contact lenses

$\checkmark$ Perform vision screening or advise the parent to bring the child for an eye exam with ophthalmologists

$\checkmark$ Encourage the child to wear corrective lenses.

\section{DIAGNOSIS}

$\checkmark \quad$ Disturbed sensory perception related to diminished vision.

$\checkmark$ Difficulty in reading related to hyperopia.

$\checkmark$ The risk of injury related to blurred vision.

$\checkmark$ Low self-esteem related to impaired vision.

\section{PERSPECTIVES AND CONCLUSION}

Refraction Error is the commonest cause of visual disability in younger students of below poverty and middle-class school children. Visual deficiency due to Uncorrected Refractive Error may have prompt and long haul effects for children and adolescents, for example, loss of educational and job potentials, loss of financial benefit to people, families and communities and reduced life expectancy. Numerous components are liable for the resulting uncorrected refractive errors such as lack of understanding and acceptance of the issue at the individual and family level, also at neighbourhood and public health level, unavailability and/or incapacity to offer refraction monitoring facilities, inadequate supply of suitable correction eye lenses and societal impediments to enforcement schemes like visual acuity screening services for people suffering from refractive blindness need to be introduced. Several research studies indicate that there was a comparatively high prevalence of Refractive Erroramong urban children than that of rural children. Students involved in outdoor games didn't have many refractive mistakes. Most of the students were involved in indoor sports, television, computers, and computer sports, etc. Some research studies show that refractive error risk factors could be prevented and help to promote awareness among students, families and especially teaching staff who play a vital role in moulding the child's future and behaviour patterns. There is a need for strong and reliable wear of spectacles should be emphasized.

\section{ACKNOWLEDGMENT}

Authors acknowledge the immense help received from the scholars whose articles are cited and included in references to this manuscript. The authors are also grateful to authors / editors / publishers of all those articles, journals, and books from which the literature for this article has been reviewed and discussed.

Conflict of interest: none declared.

Financial support: None

\section{REFERENCES}

1. Nelson V, Viswanathan G, Simon S. Prevalence and Determinants of Refractive Errors among School Children of 5th -10th Standard: A Study from South Kerala. Natl J Community Med 2018;9(11):813-818.

2. Murthy GV. Vision testing for refractive errors in schools: 'Screening' programs in schools. Community Eye Health 2000;13(33):3-5.

3. Holden BA, Sulaiman S, Knox K. The challenge of providing spectacles in the developing world. Community Eye Health 2000;13(33):9-10.

4. Dandona R, Dandona L. Refractive error blindness. Bull World Health Organ. 2001;79:237-43. 
5. McCarty CA, Taylor HR. Myopia and vision of 2020. Am J Ophthalmol 2000;129(4):525-7.

6. World Health Organisations. Global Initiative for the Elimination of Avoidable Blindness. Geneva: WHO/ PBL/97.61; Rev 2. 2006.

7. Kalikivayi V, Naduvilath TJ, Bansal AK, Dandona L. Visualimpairment in school children in Southern India. Commu Eye Care 1997;2(45):129-34.

8. Das A, Dutta H, Bhaduri G, De Sarkar A, Sarkar K, Bannerjee M.A study on refractive errors among school children in Kolkata. J Indian Med Assoc 2007;105(4):169-72.

9. Prema N. Prevalence of refractive error in school children.Indian J Sci Technol 2011;4(9):1160-1.

10. Negrel AD, Maul E, Pokharel GP, Zhao J, Ellwein LB.Refractive error study in children: Sampling and measurement methods for a multi-country survey. Am J Ophth 2000;129(4):421-6.

11. Kannan U, Rajendiran A, Yeraballi D, Shanmugavel K, John NA, Rene S. Refractive error and associated risk factors in 6-12 years schoolchildren. Natl J Physiol Pharm Pharmacol 2016;6(6):554-558.

12. Thylefors B. A global initiative for the elimination of avoidable blindness [editorial]. Am J Ophth 1998;125:90-3.

13. Pararajasegaram R. VISION 2020 - The Right to Sight: from strategies to action. Am J Ophth 1999; 128:359-60.

14. Refractive error. Wikipedia 2020. https://en.wikipedia.org/wiki/ Refractive_error (accessed June 6, 2020).

15. What is a refractive error? World Health Organization. https:// www.who.int/news-room/q-a-detail/what-is-a-refractive-error (accessed June 6, 2020).

16. Refractive errors in children, IMO, 2020. [Online]. Available: https://www.imo.es/en/refractive-errors-children. [Accessed: 06- Jun- 2020].

17. Refractive Errors, Kellogg Eye Center, Michigan Medicine [Internet]. Umkelloggeye.org. 2020 [Accessed: 06- Jun- 2020]. https://www.umkelloggeye.org/conditions-treatments/refracti veerrors\#: :text $=$ Refractive $\% 20$ error $\% 20$ means $\% 20$ that $\% 20$ the,with\%20age) $\% 2 \mathrm{C} \% 20$ and $\% 20$ astigmatism.

18. Tidake P, Madan P. Peripheral retinal findings in high Myopia in a tertiary hospital. J Datta Meghe Inst Med Sci Uni 2016;11 (4):418-422.
19. Definition of Astigmatic [Internet]. MedicineNet. 2020 [cited 13 June 2020]. Available from: https://www.medicinenet.com/ script $/$ main/art.asp? articlekey $=6755$

20. Holden BA, Fricke TR, Ho SM, Wong R, Schlenther G, Cronjé $\mathrm{S}$. et al. Global vision impairment due to uncorrected presbyopia. Arch Ophthalmol. 2008; 126: 1731-9.

21. Rasa C, Rasa L. Refractive error characteristic of the patients at the Children's Ophthalmology Outpatient Department of KaunoKlinik's Hospital (Lithuanian University of Health Sciences) from 1 January 2012 to 31 December 2012. Acta Medica Lituanica 2017; 24(2):83-92.

22. Sethu S, Bharani S, Nukella PB. Prevalence of refractive errors in children in India: a systematic review. Clin Expt Optometry 2018; 101: 495-503.

23. Dandona R, Dandona L, Srinivas M. Refractiveerror in children in a rural population in India. Invest Ophth Vis Sci 2002; 43: 615-622.

24. Murthy GVS, Gupta SK, Ellwein L, Munoz SR, Pokharel GP, Sanga L, et al. Refractive error in children in an urbanpopulation in New Delhi. Invest Ophth Vis Sci 2002; 43: 623-631.

25. Dandona R, Dandona L, Srinivas M, Giridhar P, McCarty CA, Rao GN. Population-based assessment of the refractiveerror in India: the Andhra Pradesh eye diseasestudy. Clin Exp Ophth 2002; 30: 84-93.

26. Refractive Errors National Eye Institute [Internet]. Nei.nih.gov. 2020 [cited 13 June 2020]. Available from: https://www.nei. nih.gov/learn-about-eye-health/eye-conditions-and-diseases/ refractiveerrors\#: :text $=$ There $\% 20$ are $\% 204 \% 20$ common $\% 20$ types,objects $\% 20$ look\%20blurry\%20or\%20distorted.

27. Verhoeven JVM, Hysi PG, Wojciechowski R, Fan Q, Guggenheim JA, Höhn R et al. Genome-wide meta-analyses of multiancestry cohorts identify multiple new susceptibility loci for refractive error and myopia. Nature Genet 2013;45(3):314-318.

28. Wojciechowski R. Nature and nurture: the complex genetics of myopia and refractive error. Clin Genet 2010;79(4):301-320. 